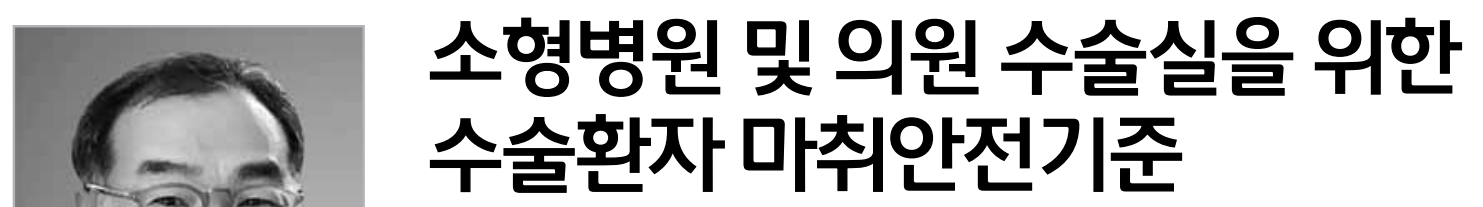

\author{
박 용 희 ${ }^{1}$. 김 태 엽 ${ }^{2}$ \\ ${ }^{1}$ 중앙대학교 의과대학 마취통증의학과 \\ ${ }^{2}$ 건국대학교 의과대학 건국대학교병원 마취통증의학과
}

\title{
Anesthesia safety standards for operating rooms of small hospitals and surgery clinics
}

\author{
Yong-Hee Park, MD' ${ }^{1}$ Tae-Yop Kim, MD² \\ ${ }^{1}$ Departement of Anesthesiology and Pain Medicine, Chung-Ang University School of Medicine, Seoul, Korea \\ ${ }^{2}$ Department of Anesthesiology, Konkuk University Medical Center, Konkuk University School of \\ Medicine, Seoul, Korea
}

\begin{abstract}
Access to surgical care and essential anesthesia is an integral part of universal health coverage. Also, increasing access to surgical care depends on a parallel increase in access to safe anesthesia. Today, five billion people (more than twothirds of the world's population) still do not have adequate, quality surgery and anesthesia care at the right time. Therefore, the World Federation of Societies of Anesthesiologists and the World Health Organization developed the International Standards for Safe Practice of Anesthesia. The standards include the following components, which are essential for the safety of patients undergoing surgical procedures: professional expertise, facilities and equipment, medications and intravenous fluids, monitoring, and anesthesia. In this article, it is emphasized that wherever and whenever possible, anesthesia should be provided, led, or overseen by an anesthesiologist. It is also strongly recommended that essential equipment is in place and adequate training to handle it safely has been provided. Unfortunately, some operating rooms of small hospitals and clinics does not meet the above standards. It may be difficult for each hospital to manage autonomously due to the lack of a unified checklist for essential standardized requirements. By introducing appropriate anesthesia safety standards in the operating rooms of small hospitals and surgery clinics, it will be possible to increase patient safety during surgery performed under general anesthesia, deep sedation, moderate sedation, or regional anesthesia. Through this process, it is expected that the mortality and morbidity rate of unexpected surgery patients can be minimized.
\end{abstract}

Key Words: Operating rooms; Anesthesia; Patient safety; Checklist

Received: September 4, 2020 Accepted: September 8, 2020

Corresponding author: Tae-Yop Kim

E-mail: taeyop@kuh.ac.kr

(C) Korean Medical Association

This is an Open Access article distributed under the terms of the Creative Commons Attribution Non-Commercial License (http://creativecommons. org/licenses/by-nc/3.0) which permits unrestricted non-commercial use, distribution, and reproduction in any medium, provided the original work is properly cited.

\section{서론}

오늘날에도 소득수준이 낮은 일부 개발도상국에서는 안 전한 수술 및 마취 서비스가 보장되지 않는 게 현실이다. 세계보건기구(World Health Organization, WHO) 발표에 의하면, 세계 인구의 $2 / 3$ 이상인 50 억 명의 사람들이 여전 히 적절한 시기의, 충분한, 양질의 수술과 마취관리를 받지 
못하고 있다[1]. 오늘날 수술적 치료로 충분히 완쾌 가능하 다고 알려진 질병이 일부 취약 지역에서는 여전히 영구적 신체적 장애 발생의 주요 원인이라고 발표하였다.

이에 세계마취과의사연합회(World Federation of Societies of Anesthesiologists, WFSA)와 $\mathrm{WHO}$ 는 시기 적절한 수술적 치료 시행과 최소 안전요건을 갖춘 마취관리, 그리고 적정한 수술기법이 환자안전을 보장하는 의료체계의 필수적 인 요소임을 주장하였고, 구현에 필요한 최소한의 필수요건 들을 제정하고 홍보하였으며, 일부 개발도상국 의료기관들 이 구현가능하도록 돕기 시작했다[2].

우리나라의 경우, 매년 의료기관 인증시스템을 거치는 대 형의료기관을 통해서, 전 국민을 상대로 가격대비 고품질의 의료서비스를 제공하고 있다는 국가적 자부심에도 불구하 고, 소규모 외과병원 및 의원(주로 성형외과의원)에서는 사 망 및 심각한 후유증을 동반하는 의료사고가 발생하고 있으 나 이에 대한 정확한 통계조차 갖고 있지 않고 있다.

만약 WFSA와 $\mathrm{WHO}$ 의 수술 안전 최소 기준을 국내 실정 에 맞게 변형하여 제정하고, 기존의 대형의료기관의 국내 의 료기관 인증체계에 해당되지 않는 소형병원 및 의원들에 적 용을 확대해 나간다면, 소형의료기관 스스로의 변화 노력과 투자를 유도할 수 있고, 아울러 인증기관 홍보를 통해 수술 환자의 선택과 이용을 독려하고 부적합한 선택을 방지함으 로써 국내 소형의료기관 수술환자의 안전을 크게 도모할 수 있을 것으로 기대된다.

\section{수술실 안전기준의 국외 현황}

1992년, WFSA에서 처음으로 수술환자 마취안전기준 을 발표하였다. 이후 2008년, $\mathrm{WHO}$ 는 안전한 수술이 생 명을 구한다는 의미로 'Safe Surgery Saves Lives'를 발족 시켰으며, 이의 한 부분으로 이 기준을 보완 발표하였다. 2018년에는 이를 국제적 표준화된 기준으로 만들어, 취약한 개발도상국 의료기관을 대상으로 이 기준을 권장하고 있는 상 태이다[3]. 이에 대한 자료는 WFSA 홈페이지에서 접근이 가 능하다[4]. 이 기준에는 크게 다음과 같은 항목들이포함된다.

\section{1. 마취 전문 의료진}

안전한 수술과 마취를 위해서는 효과적인 소통과 팀워 크가 필요하다. 모든 마취 제공 의료진은 각국이 인정하는 표준에 맞게 훈련되어야 한다. 언제 어디서나 항상 마취는 마취통증의학과 전문의에 의해 시행 및 감독되어야 한다.

\section{2. 시설 및 장비}

적절한 시설과 장비가 마취 및 회복이 이루어지는 장소에 서 사용 가능하여야 하며, 그 장비를 적절하게 다루는 교육 과 안전한 관리가 주기적으로 이루어져야 한다.

\section{3. 약물 및 정주수액}

모든 약은 알아보기 쉽게 라벨이 부착되어야 한다. 또한 전신마취 또는 깊은 진정을 시행 받는 모든 환자에서 보조적 인 산소치료가 필수적이다.

\section{4. 모니터링}

표준 수술 중/후 모니터링에는 맥박, 지속적 산소포화도, 호흡수 등이 포함된다. 기관 삽관된 환자에서는 호기말 이산 화탄소의 측정이 필요하며, 모든 환자의 감시장치 경보음(알 람)은 항상 활성화 해두어야 한다.

\section{5. 필수 마취 프로토콜}

마취통증의학과 전문의가 수술 전 환자의 상태를 평가하 며, 수술 중 관리에 책임을 지게 되고, 수술 후 회복실까지 의 이송과 이후 책임 있는 의료인에게 인계하는 과정이 필요 하다. 전신마취, 진정, 부위마취를 받은 모든 환자는 잘 정 비된 회복공간에서 마취 후 회복을 받을 수 있도록 하는 것 을 강하게 권고한다. 이를 위해 $\mathrm{WHO}$ 의 안전 수술 자가점검 표(safe surgery checklist)와 수술 후 통증관리가 포함된다.

\section{국내 소형병원 및 의원의 수술실 현황}

국내 성형수술 분야는 중국 및 아시아를 비롯, 전 세계적 으로 발달된 분야로 각광받고 있다. 하지만, 이를 시행하는 
상당수의 국내 소형병원 및 의원의 수술실 환경은 WFSA와 $\mathrm{WHO}$ 의 최소인력 및 시설기준에 크게 미치지 못하여 환자 에게 안전한 수술 및 마취관리를 제공하기에 역부족인 상 황이다. 최근 자주 접하는 성형수술 중 사망 및 불가역적인 뇌손상과 관련된 의료사고 발생은 부적격한 마취 의료인력 과 열악한 수술실 시설 및 환경이 원인이었다. 이를 단순히 의료사각지대에서 발생한 일과성 에피소드로 간주하기에는 발생빈도나 후유증이 상당히 심각한 수준이며, 사고의 대부 분이 비전문적인 의료인력, 열악한 인력 및 시설이 원인으 로 지목된다. 특히 수술환자 안전을 위한 최소한의 인적 그 리고 시설기준에 대한 국내 의료기관 평가가 소형의료기관 에 전혀 적용되지 않고 있으며, 수술자체가 의료 급여체계 에도 속하지 않아(비급여 미용 및 성형수술, 외국인 환자) 그 취약성의 정도 조차 파악되지 않고 있는 것이 현실이다. 또한, 표준화된 필수요건에 대한 통일된 체크리스트 부재 로 인해 각 병원이 자율적으로 이를 관리하고 준비하기 어 려운 실정이다.

\section{적절한 수술환자 마취안전기준의 도입방향}

국내 소형의료기관 및 성형외과의원에의 수술환자 마취 안전기준 도입은 이곳에서 시행되는 수술 중 환자안전을 보 장하는 수술 및 마취 최소 인력 및 시설기준을 제시하기 위 함이다. 이를 통해 모든 환자가 마취통증의학과 전문의에 의해, 표준화된 마취장비 및 안전장치들을 갖춘 수술실에 서 수술 받고, 수술 전후, 그리고 회복 과정에서까지 표준 화된 마취관리를 받을 수 있도록 유도하는 방안이 마련되어 야 한다. 특히, 미용 및 성형수술에 있어 환자안전을 위한 수술 전후 안전성 제고를 위해 시행되어야 할 사항들 중 하 나로 마취안전을 반드시 포함시켜야 한다는 의견은 이미 제 시된 바 있다[5]. 전신마취, 깊은 진정, 중등도의 진정이나 부위마취(척추마취, 경막외마취, 주요 상하지 신경차단) 하 에 시행되는 수술을 시행하는 성형외과의원을 비롯한 모든 의료기관에서는 마취통증의학과 전문의, 적정한 수술 및 마 취 보조인력, 약제와 치료기구, 그리고 설비와 공간을 갖춰
야한다. 다만, 국소마취만을 필요로 하는 표면상의 시술이 나 최소 진정을 하는 장소에는 해당하지 않으며, 최신지견 에 따라 주기적인 수정이 따라야 할 것이다.

\section{결론}

국내 소형병원 및 의원의 수술실에 적절한 마취안전기준 을 도입함으로써, 전신마취, 깊은 진정, 중등도의 진정이나 부위마취 하에 시행되는 수술 환자안전을 증대시키며, 예기 치 못한 수술환자의 사망률과 이환율을 최소화할 수 있을 것 으로 기대하는 바이다.

찾아보기말: 수술실; 마취; 환자안전; 점검표

\section{ORCID}

Yong-Hee Park, https://orcid.org/0000-0001-6105-7383

Tae-Yop Kim, https://orcid.org/0000-0003-0806-8969

\section{Conflict of Interest}

No potential conflict of interest relevant to this article was reported.

\section{References}

1. Meara JG, Leather AJ, Hagander L, Alkire BC, Alonso N, Ameh EA, Bickler SW, Conteh L, Dare AJ, Davies J, Mérisier ED, El-Halabi S, Farmer PE, Gawande A, Gillies R, Greenberg SL, Grimes CE, Gruen RL, Ismail EA, Kamara TB, Lavy C, Lundeg G, Mkandawire NC, Raykar NP, Riesel JN, Rodas E, Rose J, Roy N, Shrime MG, Sullivan R, Verguet S, Watters D, Weiser TG, Wilson IH, Yamey G, Yip W. Global Surgery 2030: evidence and solutions for achieving health, welfare, and economic development. Lancet 2015;386:569-624.

2.Mukhopadhyay S, Lin Y, Mwaba P, Kachimba J, Makasa E, Lishimpi K, Silverstein A, Afshar S, Meara JG. Implementing World Health Assembly Resolution 68.15: National surgical, obstetric, and anesthesia strategic plan development: the Zambian experience. Bull Am Coll Surg 2017;102:28-35.

3. Gelb AW, Morriss WW, Johnson W, Merry AF; International 
Standards for a Safe Practice of Anesthesia Workgroup. World Health Organization-World Federation of Societies of Anaesthesiologists (WHO-WFSA) International Standards for a Safe Practice of Anesthesia. Can J Anaesth 2018;65:698-708.

4. World Federation of Societies of Anesthesiologists. Safety and quality [Internet]. London: World Federation of Societies of Anesthesiologists; 2019 [cited 2020 Sep 3]. Available from: https://www.wfsahq.org/our-work/safety-quality.

5. Yoon ES, Kang SG. Perioperative considerations for patient safety in cosmetic surgery. J Korean Med Assoc 2015;58:814817. 